\title{
Eddy characteristics in the South Indian Ocean as inferred from surface drifters
}

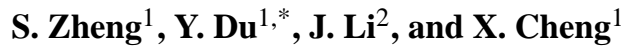 \\ ${ }^{1}$ State Key Laboratory of Tropical Oceanography, South China Sea Institute of Oceanology, \\ Chinese Academy of Sciences, Guangzhou 510301, China \\ ${ }^{2}$ Naval Institute of Hydrographic Surveying and Charting, Tianjin 300061, China \\ *now at: State Key Laboratory of Tropical Oceanography, South China Sea Institute of Oceanology, \\ Chinese Academy of Sciences, 164 West Xingang Road, Guangzhou 510301, China
}

Correspondence to: Y. Du (duyan@scsio.ac.cn)

Received: 22 October 2014 - Published in Ocean Sci. Discuss.: 11 December 2014

Revised: 15 April 2015 - Accepted: 24 April 2015 - Published: 12 May 2015

\begin{abstract}
Using a geometric eddy identification method, cyclonic and anticyclonic eddies from submesoscale to mesoscale in the South Indian Ocean (SIO) have been statistically investigated based on 2082 surface drifters from 1979 to 2013. A total of 19252 eddies are identified, $60 \%$ of them anticyclonic eddies. For the submesoscale eddies (radius $r<10 \mathrm{~km}$ ), the ratio of cyclonic eddies (3183) to anticyclonic eddies (7182) is 1 to 2 . In contrast, the number of anticyclonic and cyclonic eddies with radius $r \geq 10 \mathrm{~km}$ is almost equal. Mesoscale and submesoscale eddies show different spatial distributions. Eddies with radius $r \geq 100 \mathrm{~km}$ mainly appear in the Leeuwin Current, a band along $25^{\circ} \mathrm{S}$, Mozambique Channel, and Agulhas Current, areas characterized by large eddy kinetic energy. The submesoscale anticyclonic eddies are densely distributed in the subtropical basin in the central SIO. The number of mesoscale eddies shows statistically significant seasonal variability, reaching a maximum in October and minimum in February.
\end{abstract}

\section{Introduction}

The South Indian Ocean (SIO) has unique current systems. A schematic general circulation diagram is shown in Fig. 1. The South Equatorial Current (SEC) in the SIO is in large part supplied by the Indonesian Throughflow (ITF). The SEC splits into the Northeast Madagascar Current (NEMC) and Southeast Madagascar Current (SEMC) when it reaches the east coast of Madagascar near $17^{\circ} \mathrm{S}$ (Schott et al., 2001,
2009). The NEMC flows around the north tip of Madagascar at Cape Amber to the coast of Tanzania at about $12^{\circ} \mathrm{S}$ and splits into northward and southward flows. The northward branch of NEMC feeds into the East African Coast Current (EACC), and the southward branch joins the Mozambique Channel throughflow with anticyclonic eddies (de Ruijter et al., 2002; Schouten et al., 2003; Ridderinkhof et al., 2010). The SEMC joins the Agulhas Current after passing south of Madagascar and features with plentiful eddies and dipoles (de Ruijter et al., 2004; Quartly et al., 2006). The Agulhas Current carries warm and saline water from the Indian Ocean to the Atlantic Ocean through the Agulhas Leakage (Gordon et al., 1992; Donners et al., 2004). The Agulhas retroflection reenters the SIO as a broad northeastward flow and extends to the west coast of Australia (Schott et al., 2009). The Leeuwin Current (LC) off Western Australia is an anomalous poleward-flowing eastern boundary current due to a large meridional pressure gradient (Godfrey and Ridgway, 1985; Feng et al., 2005). It carries warm, low-salinity water southward along the coast of Western Australia (Cresswell and Golding, 1980; Pearce, 1991). The LC has seasonal variation: it flows strongly in the austral winter with the weakest southerly winds (Cresswell, 1991; Fieux et al., 2005) and strengthening alongshore pressure gradient (Godfrey and Ridgway, 1985; Potemra, 2001).

Mesoscale eddies are an important ocean dynamic phenomenon and provide important material and dynamical fluxes for the equilibrium balances of the general circulation and climate (McWilliams, 2013). Mesoscale eddies can 


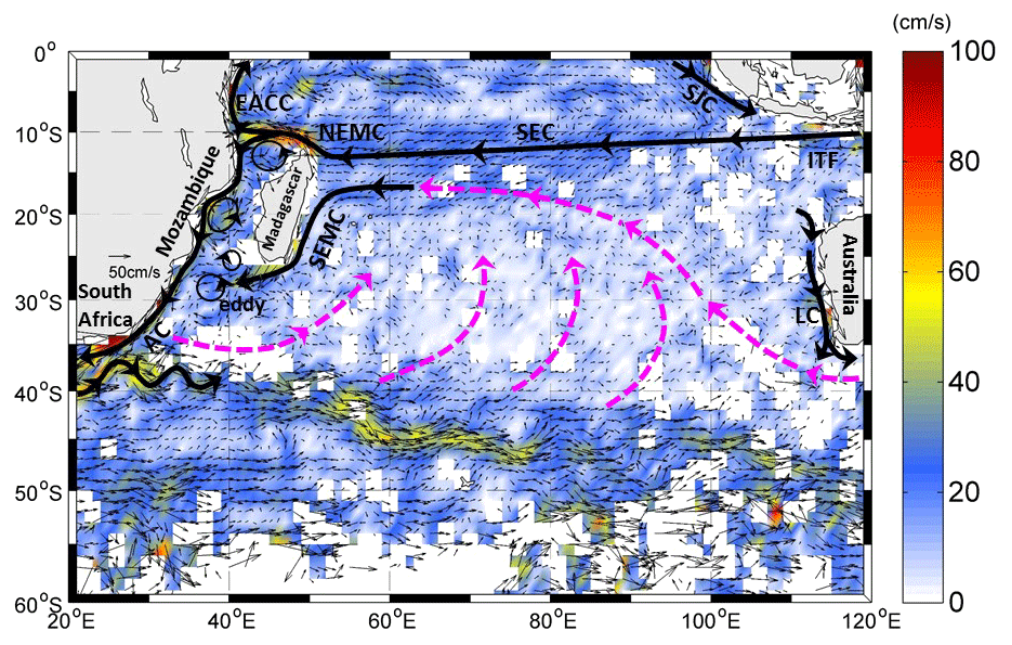

Figure 1. A schematic diagram of identified current branches in the South Indian Ocean, modified from Schott et al. (2009) and Beal et al. (2011). Mean flow in the SIO is from the average of drifter-detected velocity in bins with $1^{\circ} \times 1^{\circ}$ resolution, and velocity less than $5 \mathrm{~cm} \mathrm{~s}^{-1}$ is omitted (for data details refer to Lumpkin and Johnson, 2013). Schematic current branches are the South Java Current (SJC), Indonesian Throughflow (ITF), South Equatorial Current (SEC), Northeast and Southeast Madagascar Current (NEMC and SEMC), East African Coast Current (EACC), AC (Agulhas Current), and Leeuwin Current (LC). The subsurface return flow is shown in magenta.

cause heat and salt transports (Qiu and Chen, 2005; Volkov et al., 2008; Dong et al., 2014), and eddy-induced zonal mass transport is comparable in magnitude with that of largescale circulation (Zhang et al., 2014). Mesoscale eddies modulate nutrient flux into the euphotic zone through vertical and horizontal transport (Falkowski et al., 1991; Aristegui et al., 1997; Crawford et al., 2005). Submesoscale eddies also play a key role in biogeochemical budgets through intense upwelling of nutrients, subduction of plankton and horizontal stirring (Ledwell et al., 1993; Abraham, 1998; Abraham et al., 2000; Lévy et al., 2001; Lévy and Klein, 2004). Mesoscale eddies in the SIO have been studied using satellite data (e.g., Palastanga et al., 2006; Chelton et al., 2011), ocean modeling (e.g., Backeberg et al., 2008) and in situ observations (e.g., de Ruijter et al., 2004; Ridderinkhof et al., 2010). In the southeast Indian Ocean (IO), altimetry measurements showed that anticyclonic eddies propagate westward and equatorward, and cyclonic eddies propagate poleward (Morrow et al., 2004). The eddy kinetic energy (EKE) shows a seasonal cycle with a maximum in austral summer and a minimum in austral winter (Jia et al., 2011). In austral spring, enhanced heat flux forcing of combined meridional Ekman and geostrophic convergence strengthens the upperocean meridional temperature gradient and intensifies the vertical velocity shear. This modulation of the vertical velocity shear changes the intensity of baroclinic instability associated with the surface-intensified South Indian Countercurrent (SICC) and underlying SEC system, leading to the seasonal variations of EKE (Jia et al., 2011). In the Mozambique Channel, satellite SeaWiFs ocean color snapshots showed large anticyclonic rings intermittently propagating poleward along the western edge of the channel (Quartly and Srokosz,
2004). Analysis of sea surface height (SSH) suggested a connection between mesoscale eddy activity around Madagascar and large-scale interannual variability in the SIO (e.g., Palastanga et al., 2006). Long-term moorings showed that four to five anticyclonic eddies drifted southwards through the channel in each year (Ridderinkhof et al., 2010). Southwest of Madagascar, cruise data showed anticyclonic eddies propagated mostly westward, while cyclonic eddies diverged more between west and southwest (de Ruijter et al., 2004). Altimetry and sea surface temperature data showed that a number of westward-propagating eddies exist along the zonal band near $25^{\circ} \mathrm{S}$ (Quartly et al., 2006). In the Agulhas Current region, anticyclonic eddies propagate northwestward and enter the southeast Atlantic Ocean (Backeberg et al., 2008).

Though a few studies have worked on the mesoscale eddies in the SIO, the investigation of eddy characteristics based on in situ observation is far from enough. Compared with altimetry measurements, surface drifters give fine spatial and temporal resolutions. Due to the long distance between satellite tracks, altimetry can hardly detect eddies with radius $r<40 \mathrm{~km}$ (e.g., Chelton et al., 2011). Whereas surface drifters can detect submesoscale eddies with radius $r<10 \mathrm{~km}$ (Berti et al., 2011; Li et al., 2011; Schroeder et al., 2012). Surface drifters have a $6 \mathrm{~h}$ temporal resolution, much more than altimetry data which, so far, usually have 7- or 1-day intervals available to the public. Surface drifters give reliable in situ observations and have been extensively used in other ocean regimes (Deverdiere, 1983; Chaigneau and Pizarro, 2005; Hamilton, 2007; Li et al., 2011; Zu et al., 2012).

The present study investigates characteristics of eddy spatial and temporal distribution in the SIO based on in situ surface drifters. We wish to address the following questions: do 


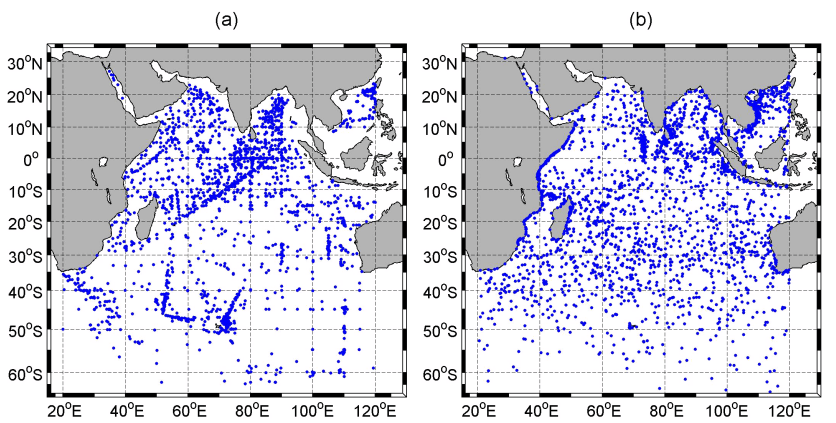

Figure 2. (a) Release and (b) terminal locations of surface drifters.

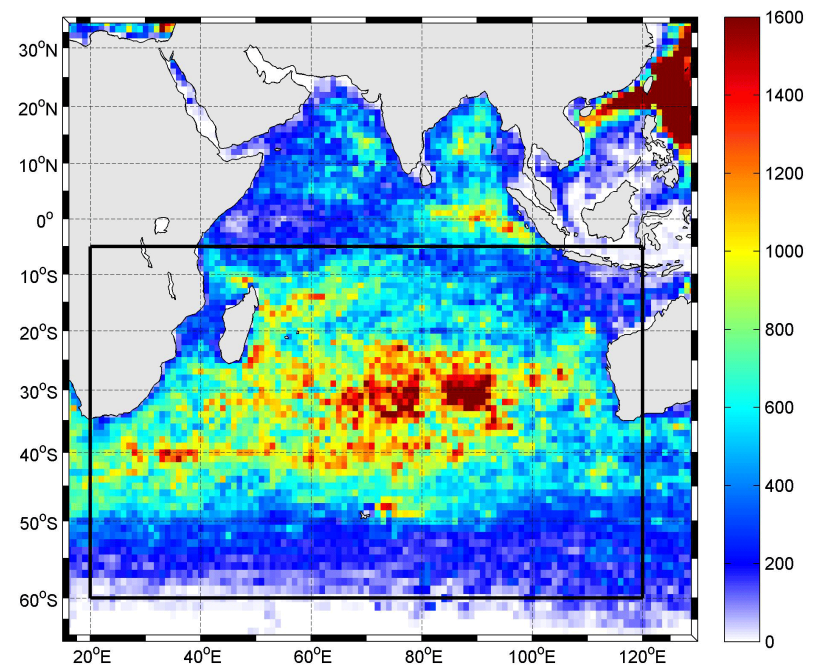

Figure 3. Number of drifters passing through each $1^{\circ} \times 1^{\circ}$ bin in their trajectories.

eddies have uniform spatial distribution? If not, what is different between cyclonic and anticyclonic eddies with different radii. Does the number of eddies have seasonal variation? In this paper, spatial distribution and temporal variation of cyclonic and anticyclonic eddies with different radii are studied. The paper may extend our knowledge of mesoscale and submesoscale eddies from in situ observations and provide a background for biochemical study.

The rest of this paper is organized as follows. Data and methods are introduced in Sect. 2. Eddy characteristics and eddy statistics in the SIO are described in Sect. 3. Discussion and a summary are given in Sect. 4.

\section{Data and methods}

The surface satellite-tracked drifter data used in this paper are archived at the Atlantic Oceanographic and Meteorological Laboratory (AOML). The AOML receives drifter positions from the Doppler shift of its transmission from the American-French satellite-based system (Argos, Lumpkin and Pazos, 2007). The Drifter Data Assembly Center (DAC) at AOML assembles these raw data, applies quality control
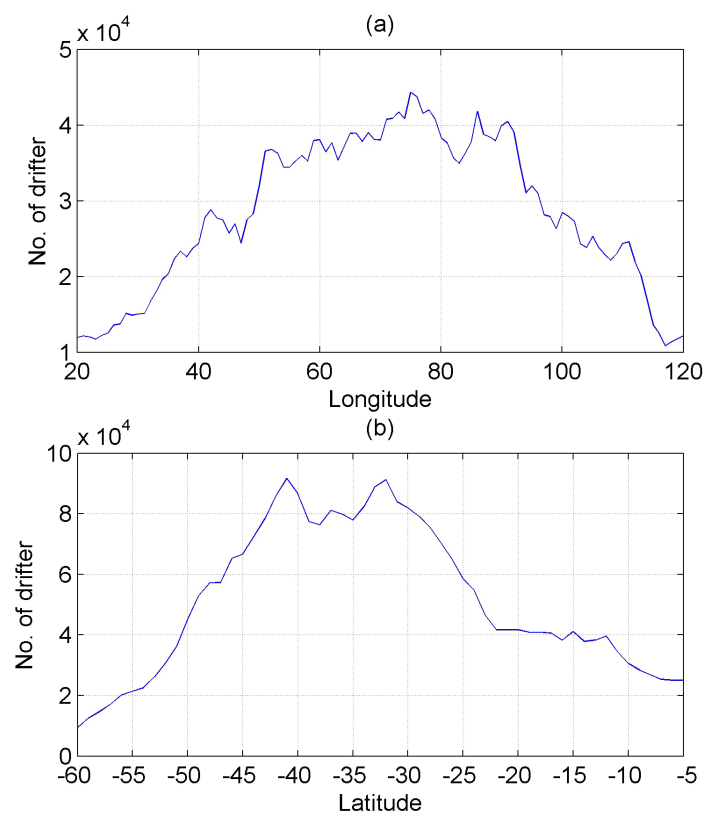

Figure 4. (a) Meridional and (b) zonal accumulated number of drifters as a function of longitude and latitude, respectively.

procedures, and interpolates them via the kriging method to regular $6 \mathrm{~h}$ intervals (Hansen and Herman, 1989; Hansen and Poulain, 1996). The drifters have their drogues centered at $15 \mathrm{~m}$ depth to measure surface currents, and a semi-rigid material throughout the drogue can provide support for the drifter to maintain its shape in high-shear flows (Lumpkin and Pazos, 2007). In this study, surface drifter data from February 1979 to September 2013 are used. There were a total of 2226 drifters released in the IO (Fig. 2a), and their distribution was not uniform. Drifters covered most regions in the Arabian Sea and Bay of Bengal, but drifters were sparse south of $20^{\circ} \mathrm{S}$. A total of 2567 drifters terminated (Fig. 2b) in the IO, a little more than those released in the IO; some came from the adjacent oceans. Drifters were released in particular areas, like along the commercial tracks, but their terminations were uniform. Figure 3 shows drifter numbers passing through each $1^{\circ} \times 1^{\circ}$ bin in their trajectories. Despite release locations mainly north of $20^{\circ} \mathrm{S}$, drifters prefer to stay in the central SIO. Therefore, we select all 2082 drifters captured in the region of $20-120^{\circ} \mathrm{E}, 5-60^{\circ} \mathrm{S}$ (rectangle line in Fig. 3) to study the eddy characteristics. We also calculate drifter numbers as a function of longitude and latitude. There are two maxima near longitudes 75 and $90^{\circ} \mathrm{E}$ (Fig. 4a), and two maxima near latitudes 41 and $33^{\circ} \mathrm{S}$ (Fig. 4b). These maxima are corresponding to the NEMC, SEMC, Agulhas Current, and subtropical convergent region, respectively. Figure 5a shows the number of drifter observations in each year since 1985, and Fig. 5b shows the number of drifter observations in each climatological calendar month. Although surface drifter plans began in 1979, observations were sparse in the SIO be- 

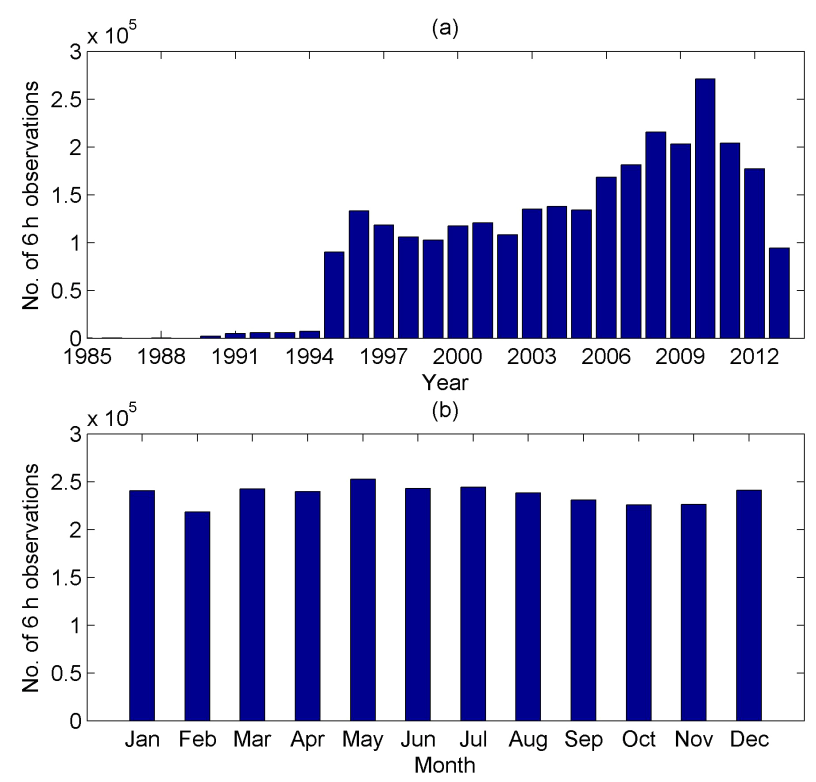

Figure 5. (a) Number of all drifter observations in each year since 1985 , each observation is one $6 \mathrm{~h}$ position from a drifter trajectory. (b) Number of all drifter observations at $6 \mathrm{~h}$ intervals in each climatological calendar month.

fore 1995 (Fig. 5a). The number of observations increased dramatically since 1995 and reached a maximum in 2010. Fortunately, it does not show significant seasonal difference (Fig. 5b).

A geometric eddy identification method based on surface drifters has been successfully used in the northeastern Atlantic Ocean (Lankhorst, 2006; Lankhorst and Zenk, 2006), Kuroshio Extension region (Dong et al., 2011) and northern South China Sea (Li et al., 2011). In our study, we use the method developed by Li et al. (2011) to identify eddies in the SIO. The method is based on definition of a closed loop with the starting point overlapped by the ending point. Eddies are identified through four steps (see more detail in Li et al., 2011): first, find overlapping points along surface drifter trajectories. Second, perform quality control on overlapping points to eliminate false points and avoid losing internal overlapping points. Third, determine polarity of loops (cyclonic or anticyclonic drifter track). In the Southern Hemisphere, when a surface drifter is caught by a cyclonic (anticyclonic) eddy it will make clockwise (counterclockwise) loops. Fourth, cluster loops to oceanic eddies. Some drifters can be trapped in eddies for a long time period (figure is omitted). The mean number of (drifter-tracked) rotations for individual large cyclonic (anticyclonic) eddies is 2.22 (2.23), while for submesoscale cyclonic (anticyclonic) eddies it is 2.49 (3.29). Submesoscale eddies trend to rotate more times than large mesoscale eddies. We cluster drifter loops with more than one rotation to one eddy according to method of eddy identification ( $\mathrm{Li}$ et al., 2011). The loop center is estimated by geometrically averaging all the sample points in

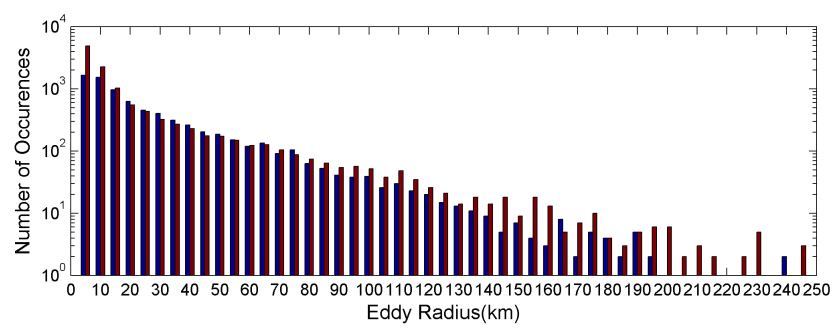

Figure 6. Histogram of eddy occurrence with a bin width of $5 \mathrm{~km}$ as eddy radius. Blue and red bars indicate cyclonic and anticyclonic eddies, respectively.

the loop. The loop radius is defined by the mean distance between all loop points to the loop center. The eddy radius is defined by mean radius of clustered loops. To remove inertial oscillation, eddies with a period less than double the local inertial oscillation period $(T)$ are not included. The inertial oscillation period is calculated as follows: $T=\frac{2 \pi}{f}$, where $f=2 \Omega \sin (\varphi), f$ is the Coriolis parameter, $\Omega$ is the earth rotating frequency $\left(\Omega=2 \pi / 24 \mathrm{~h}=7.27 \times 10^{-5} \mathrm{~s}^{-1}\right)$, and $\varphi$ is the latitude of the eddy centers.

To compare with eddies detected by surface drifters, mesoscale eddies in altimeter observation of SSH are also used. The mesoscale eddies were detected from SSH-based automated eddy identification procedures distributed by Chelton et al. (2011).

The gridded sea level anomaly (SLA) data product with $1 / 3^{\circ}$ resolution is used to calculate EKE: these SLA data are distributed by Archiving, Validation, and Interpretation of Satellite Oceanographic data (AVISO). EKE are calculated by geostrophic velocity anomalies (Pujol and Larnicol, 2005; Jia et al., 2011) as follows: $\mathrm{EKE}=\frac{1}{2}\left({U_{\mathrm{g}}^{\prime}}^{2}+V_{\mathrm{g}}^{\prime 2}\right), U_{\mathrm{g}}^{\prime}=$ $-\frac{g}{f} \frac{\Delta \eta^{\prime}}{\Delta y}$ and $V_{\mathrm{g}}^{\prime}=\frac{g}{f} \frac{\Delta \eta^{\prime}}{\Delta x}$, where $U_{\mathrm{g}}^{\prime}$ and $V_{\mathrm{g}}^{\prime}$ are the geostrophic velocity anomalies, and $\Delta \eta^{\prime}$ is the SLA.

\section{Eddy characteristics and statistics in the SIO}

\subsection{Number and radius}

On the basis of the surface satellite-tracked drifter data, a total of 57228 loops were detected in the SIO. Among them 22773 are cyclonic loops and 34455 are anticyclonic loops. After clustering the loops, a total of 19252 eddies are detected with 7657 cyclonic eddies (clockwise) and 11595 anticyclonic eddies (counterclockwise). The number of anticyclonic eddies account for $60 \%$ of eddies. Figure 6 shows the histogram of eddy radii with bin widths of $5 \mathrm{~km}$, in which blue (red) bars depict cyclonic (anticyclonic) eddies. Submesoscale eddies (radius $r<10 \mathrm{~km}$ ) are identified successfully, and its number is 10365 accounting for $54 \%$ of total eddies. In terms of submesoscale eddies, the ratio of cyclonic eddies to anticyclonic eddies is 1 to 2 . With submesoscale eddies excluded, the mean radii are 39,37 , and $41 \mathrm{~km}$ for 

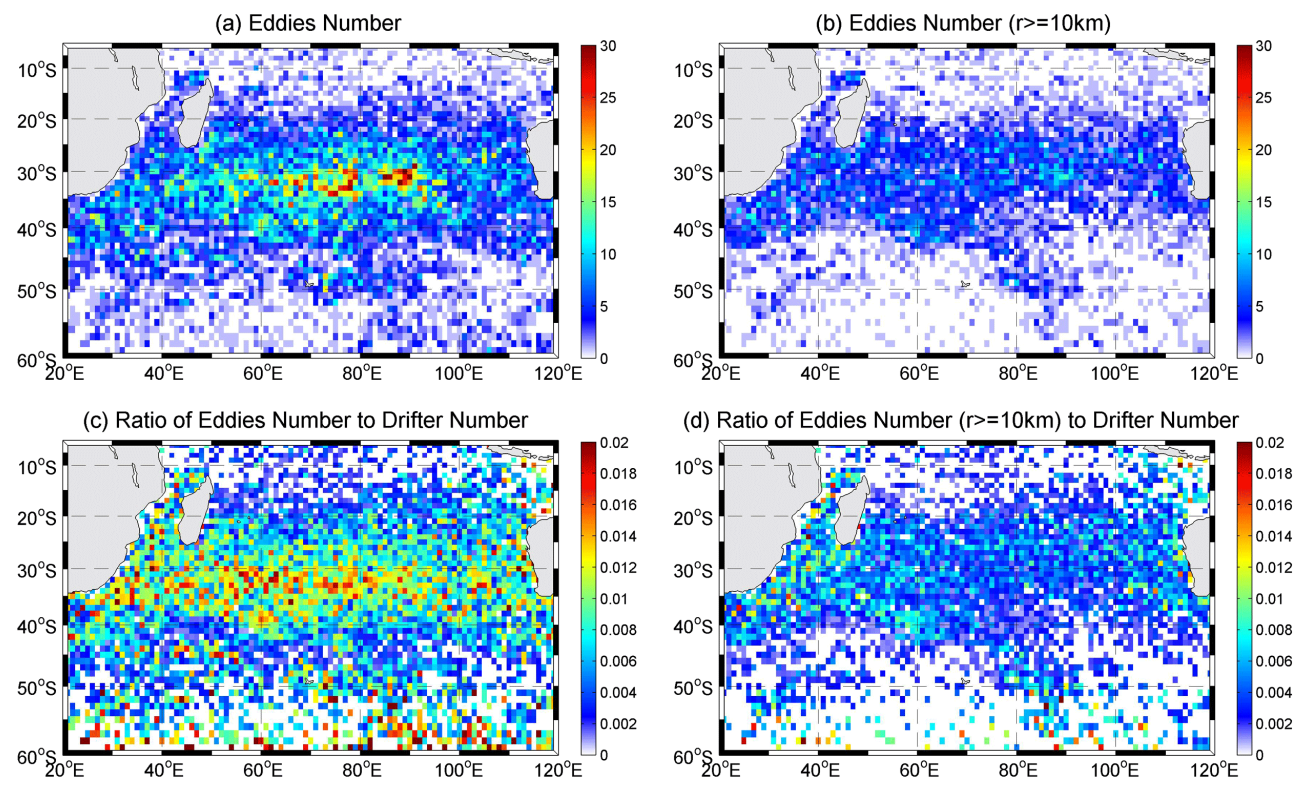

Figure 7. (a) Number of eddies detected in $1^{\circ} \times 1^{\circ}$ bins. (b) Number of eddies with radii equal or greater than $10 \mathrm{~km}$ detected in $1^{\circ} \times 1^{\circ}$ bins. (c) Ratio of number of eddies to number of drifters in $1^{\circ} \times 1^{\circ}$ bins. (d) Ratio of number of eddies with radii equal or greater than $10 \mathrm{~km}$ to number of drifters in $1^{\circ} \times 1^{\circ}$ bins.

all, cyclonic, and anticyclonic eddies, respectively. As documented by Chaigneau and Pizarro (2005), if drifters are on average statistically evenly distributed along the eddy radius $R$, the probability density $p(r, \theta)$ of finding the drifter at a radius $r$ and direction $\theta$ relative to the eddy center is constant. The formulate is as follows: $p(r, \theta)=\frac{1}{\int_{0}^{R 2 \pi} \int d r d \theta}=\frac{1}{\pi R^{2}}$. The mean distance $\overline{R_{1}}$, or expectation $E(r)=\int_{0}^{R} \int_{0}^{2 \pi} r^{2} p(r, \theta) d r d \theta$ of a drifter from the eddy center is then given by $\overline{R_{1}}=2 R / 3$. The mean radius $\overline{R_{1}}$ of all eddies is $19 \mathrm{~km}$ in the SIO, implying a characteristic eddy diameter $2 R$ of $57 \mathrm{~km}$. This order of magnitude is consistent with the mean Rossby deformation radius $(20-100 \mathrm{~km})$ in the region of $10-50^{\circ} \mathrm{S}$ in the SIO (Chelton et al., 1998).

\subsection{Spatial distribution}

Figure $7 \mathrm{a}$ shows eddies are densely distributed in the subtropical region in the central SIO. As drifters are also densely distributed in the central SIO (Fig. 3), a question is whether the spatial distribution of eddies depends on that of drifter number or not. The ratio of the number of eddies to the number of drifters is relatively high in the band of $25-40^{\circ} \mathrm{S}$ (Fig. 7c), which suggests that more drifters (Fig. 3) would give more detected eddies. When the submesoscale eddies (radii $<10 \mathrm{~km}$ ) are excluded, the spatial distribution of the number of eddies is almost uniform (Fig. 7b), and the relatively large ratio is mainly in the Mozambique Channel and Agulhas Current (Fig. 7d), which is not fully correspond- ing to the drifter distribution (Fig. 3). The method of eddy detection still works well in the sparse drifter region. We separate cyclonic eddies (Fig. 8a) from anticyclonic eddies (Fig. 8c) to study their spatial distribution in detail. The cyclonic eddies have a relatively uniform spatial distribution and in most regions are fewer than 15 in $1^{\circ} \times 1^{\circ}$ bins. In contrast, the anticyclonic eddies are densely distributed in the central SIO with more than 15 eddies in $1^{\circ} \times 1^{\circ}$ bins. When submesoscale eddies are excluded, cyclonic (Fig. 8b) and anticyclonic eddies (Fig. 8d) show similar spatial distributions. Therefore, different spatial distributions according to eddy size imply that eddy properties also affect the results irrespective of drifter density.

Spatial distribution of eddies varies with the size. All eddies are categorized into four groups according to their size: large eddies $(r \geq 100 \mathrm{~km})$, medium eddies $(100 \mathrm{~km}>r>60 \mathrm{~km})$, small eddies $(60 \mathrm{~km} \geq r \geq 10 \mathrm{~km})$, and submesoscale eddies $(r<10 \mathrm{~km})$. Figure 9 shows the trajectories of drifters in cyclonic eddies (blue lines) and anticyclonic eddies (red lines) for the four groups, and the numbers of cyclonic (anticyclonic) eddies are 203 (340), 565 (619), 3706 (3454), and 3183 (7182), respectively. We also used two loops as a criterion for eddy detection (figure is omitted), and the result was similar to Fig. 9. Actually, eddies with periods less than double the local inertial oscillation period are excluded to remove inertial oscillation, and loops are clustered to one eddy in detection algorithm. The radii of eddies are smaller than the basin scale (Fig. 6) in our study. There are more large anticyclonic eddies than cyclonic ones. Large eddies are numerous in the Leeuwin Current, a band along $25^{\circ} \mathrm{S}$, Mozambique Channel, and Agulhas Current (Fig. 9a). 

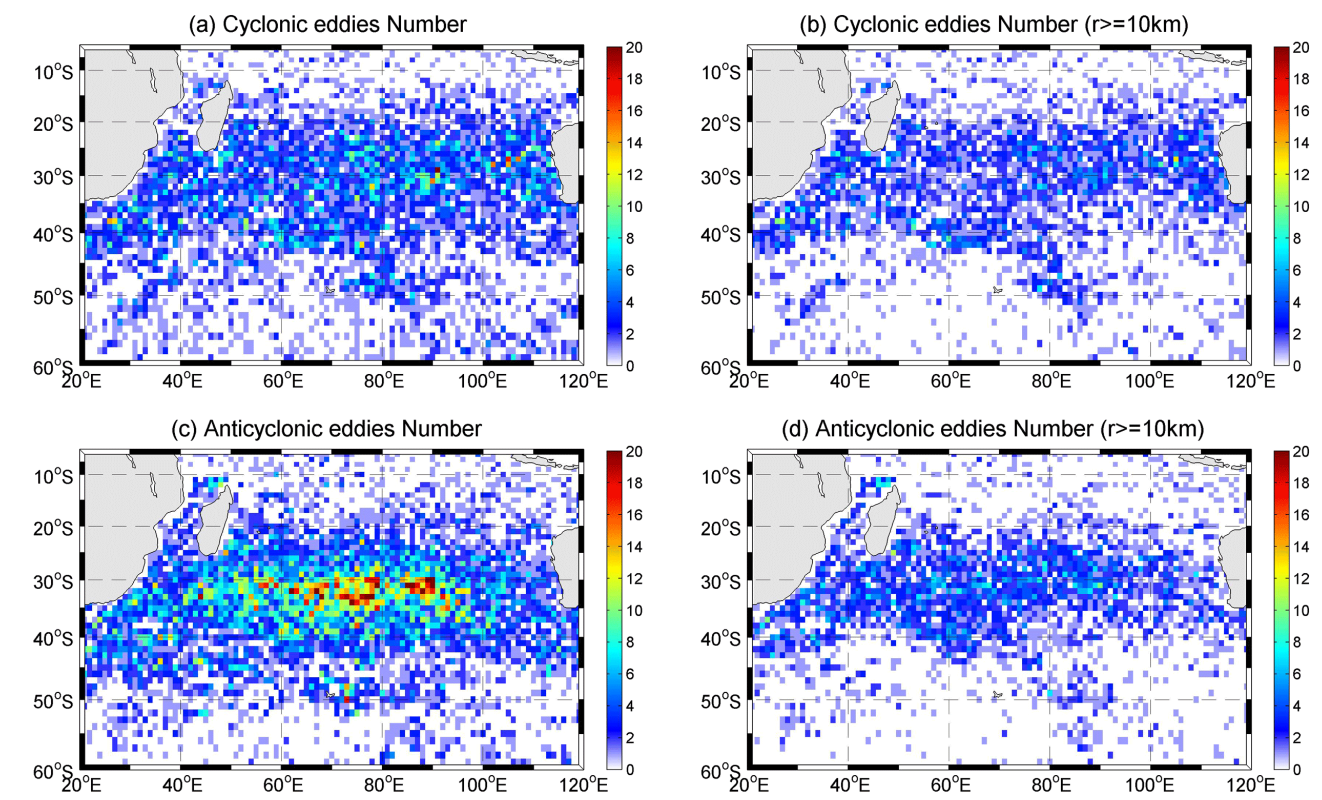

Figure 8. (a) Number of cyclonic eddies detected in $1^{\circ} \times 1^{\circ}$ bins. (b) Number of cyclonic eddies with radii equal or greater than $10 \mathrm{~km}$ detected in $1^{\circ} \times 1^{\circ}$ bins. (c) Same as (a) but for anticyclonic eddies. (d) Same as (b) but for anticyclonic eddies.

(a) $r>=100 \mathrm{~km}$

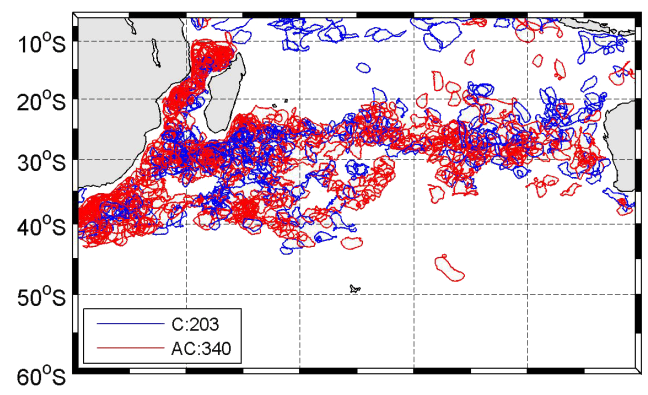

(c) $10 \mathrm{~km}<=r<=60 \mathrm{~km}$

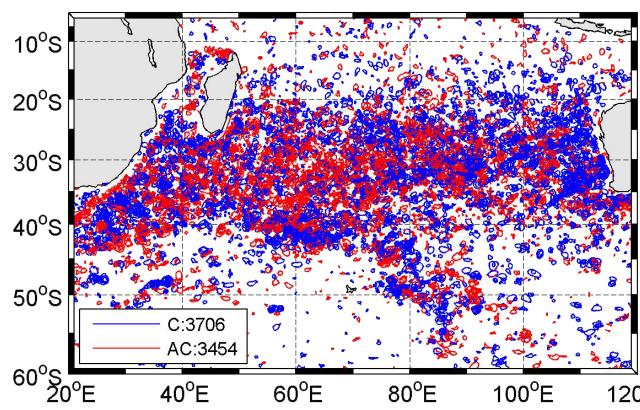

(b) $60 \mathrm{~km}<\mathrm{r}<100 \mathrm{~km}$

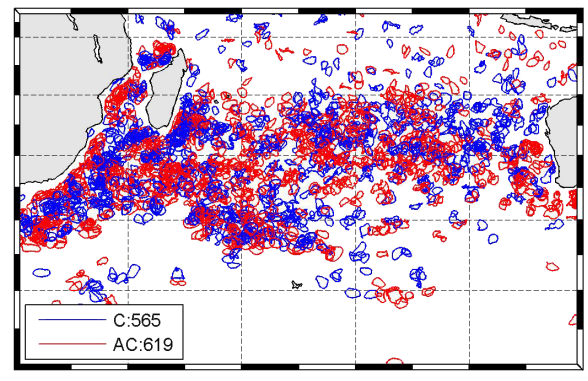

(d) $r<10 \mathrm{~km}$

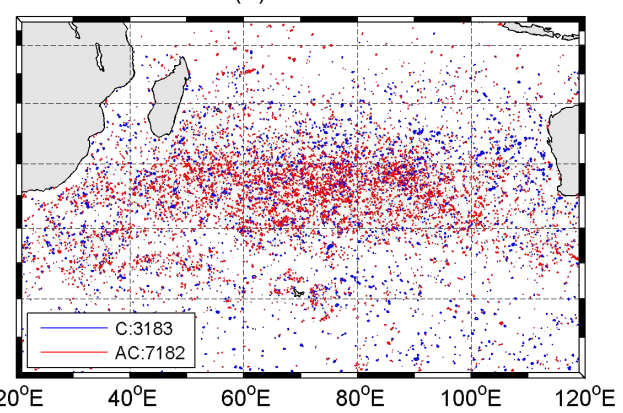

Figure 9. The distribution of cyclonic and anticyclonic eddies detected from drifters in the SIO.

The climatological mean EKE in Fig. 10 is mean EKE derived from AVISO SLA data from 1993 to 2012. When we regard this climatological mean EKE as background EKE, the mean EKE at the eddies' centers (along the eddies' trajectories) could be calculated through linear interpolation in the SIO for large eddies, medium eddies, small ed- dies and submesoscale eddies, giving $357(346) \mathrm{cm}^{2} \mathrm{~s}^{-2}, 301$ (298) $\mathrm{cm}^{2} \mathrm{~s}^{-2}, 243(243) \mathrm{cm}^{2} \mathrm{~s}^{-2}$, and $167(168) \mathrm{cm}^{2} \mathrm{~s}^{-2}$, respectively. The mean EKE for large eddies is larger than for other groups of eddies. Five regions are selected in the SIO - including the Leeuwin Current at the eastern boundary, a band along $25^{\circ} \mathrm{S}$, Mozambique Channel and Agulhas Cur- 


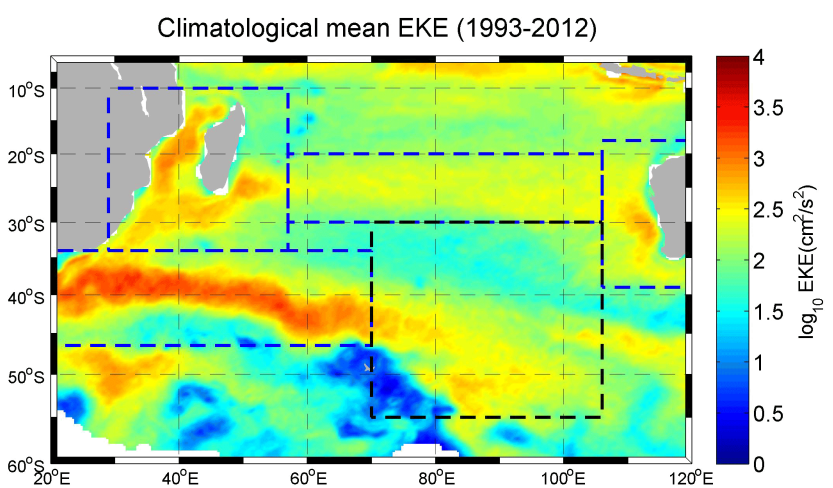

Figure 10. Climatological mean of eddy kinetic energy in the SIO derived from altimetry data over 1993-2012. Blue rectangles represent the Leeuwin Current region $\left(106-120^{\circ} \mathrm{E}, 18-39^{\circ} \mathrm{S}\right.$ ), a band along $25^{\circ} \mathrm{S}\left(57-106^{\circ} \mathrm{E}, 20-30^{\circ} \mathrm{S}\right)$, Mozambique Channel $\left(29-57^{\circ} \mathrm{E}, 10-34^{\circ} \mathrm{S}\right)$ and Agulhas Current $\left(20-70^{\circ} \mathrm{E}, 34-46.5^{\circ} \mathrm{S}\right)$. Black rectangle represents the interior ocean $\left(70-106^{\circ} \mathrm{E}, 30-55^{\circ} \mathrm{S}\right)$ in the SIO.

rent at the western boundary, and the interior Ocean (rectangles in Fig. 10) - to study relationships between different kinds of eddies and mean EKE. The results show that the mean EKE of large eddies at the eastern boundary, in a band along $25^{\circ} \mathrm{S}$ and at the western boundary, is larger than for other groups, but this comparison is reversed in the interior ocean. The number of large eddies in large EKE regions is 457 accounting for $84 \%$ of all large eddies in the SIO. Therefore, large eddies tend to populate regions with large EKE. We also calculate the ratio of number of eddies where mean EKE is equal to or greater than $200 \mathrm{~cm}^{2} \mathrm{~s}^{-2}$ to the number of all eddies, which is similar for criterion $250 \mathrm{~cm}^{2} \mathrm{~s}^{-2}$. This ratio is larger (for large eddies) than for other eddy groups in large EKE regions, except in the interior ocean. Hence, large eddies populate a band along $25^{\circ} \mathrm{S}$ and the eastern and western boundaries with large EKE. Whereas in the interior ocean with small EKE the number of large eddies is small. Although many drifters can be found northeast of Madagascar (Fig. 3), no large eddies are detected there. There are few large eddies south of $43^{\circ} \mathrm{S}$, probably due to the Rossby deformation radius of less than $30 \mathrm{~km}$ (Chelton et al., 1998). The spatial distribution of large cyclonic eddies and anticyclonic eddies are different. Anticyclonic eddies are rich in the Mozambique Channel and Agulhas Current, while many cyclonic eddies appear south of Madagascar. In the Mozambique Channel, the shape of large eddies is restrained by coastline in a northeast-southwest direction, and large eddies show similar character with eddies detected by in situ observations (de Ruijter et al., 2002; Swart et al., 2010) and altimetry (Schouten et al., 2003), which also validated our method of eddy detection. At same time, large eddies appear mainly along the center line of the Mozambique Channel (Fig. 9a), and the western boundary current does not show strong influence on eddies in this region. Medium eddies have a similar spatial distribution to that of large eddies but occur in a wider area. The number of eddies is about twice the number of large eddies (Fig. 9b). Unlike other kinds of eddies, the number of small cyclonic eddies is greater than small anticyclonic eddies (Fig. 9c). The small eddies are in the region ranging from 20 to $44^{\circ} \mathrm{S}$, and the distribution of cyclonic eddies appear in the northeast-southwest direction west of Australia. Here the distribution of cyclonic eddies is consistent with poleward propagation at the eastern boundary, which can be explained by theories for vortex propagation on a $\beta$-plane (Morrow et al., 2004). The submesoscale eddies are densely distributed over the entire SIO (Fig. 9d), with a similar pattern to that of total eddies (Fig. 7a). The submesoscale anticyclonic eddies are densely distributed in the subtropical basin in the central SIO. The area with a high number of submesoscale anticyclonic eddies agrees well with the location of garbage patches (Maximenko et al., 2012; Van Sebille et al., 2012). The appearance of more submesoscale anticyclonic eddies maybe come from drifter aggregation, maintained by converging Ekman currents (Maximenko et al., 2012), and Fig. 3 also reveal that drifters aggregated in the central SIO. At the same time, the surface current in the region of drifter aggregation is counterclockwise. Hence, there are more anticyclonic eddies than cyclonic eddies. However, it is still unclear why such a mechanism only affects submesoscale eddies. Nakamura et al. (2012) found that counterclockwise submesoscale eddies are generally larger in number than cyclonic submesoscale eddies near the Kuril Islands. The possible causes of such asymmetry are planetary-vorticity tube stretching and asymmetric advection by the rotating tidal flow. The mechanism of submesoscale eddy generation needs study in the future.

\subsection{Temporal variations}

The occurrence of eddies shows significant seasonal variations (Fig. 11a), with more eddies in austral autumn and winter and fewer eddies in austral spring and summer. The number of cyclonic eddies reaches a maximum in August, whereas the number of anticyclonic eddies reaches a minimum in September. If the submesoscale eddies are not included, temporal variations of mesoscale eddies (Fig. 11b) are different from that of all eddies (Fig. 11a). The number of mesoscale eddies reaches a maximum in October and a minimum in February, and the cyclonic and anticyclonic mesoscale eddies show similar seasonal variations.

To compare with seasonal variability of eddies detected from satellite observations, we use eddy data provided by Chelton et al. (2011). Because the number of drifter observations has increased dramatically since 1995 (Fig. 5a), we check eddy fields derived from altimetry SSH from 1995 to 2012. The result represents a similar temporal distribution as in Fig. 11b. There are more eddies generated in austral spring (Fig. 12), and fewer eddies in austral summer. 
(a) All Eddies

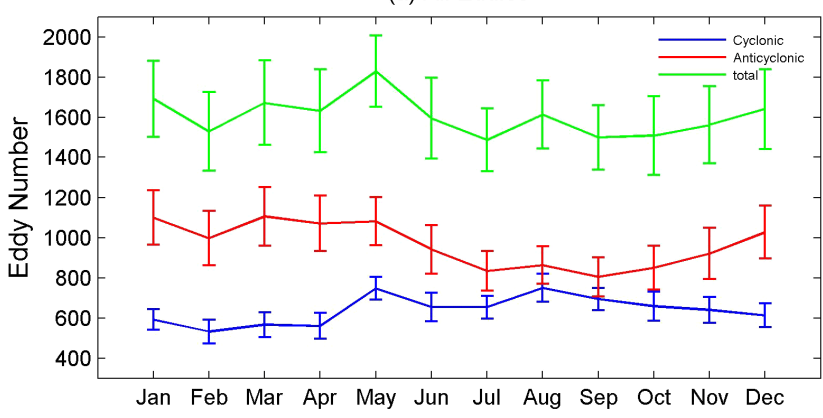

(b) Eddies radii greater than $10 \mathrm{~km}$

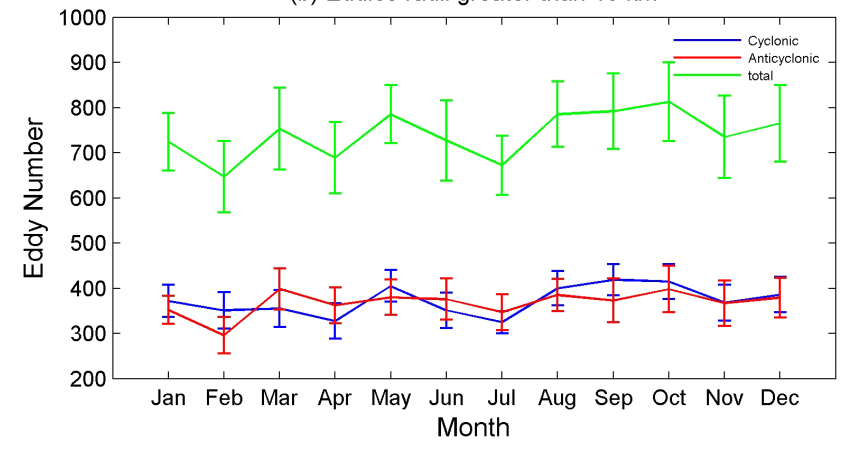

Figure 11. (a) The number of eddies as a function of the calendar months for cyclonic (blue), anticyclonic (red), and both types of eddies (green). The bars indicate the standard error of eddy number estimates. (b) as in (a), but for mesoscale eddies with radius larger than $10 \mathrm{~km}$.

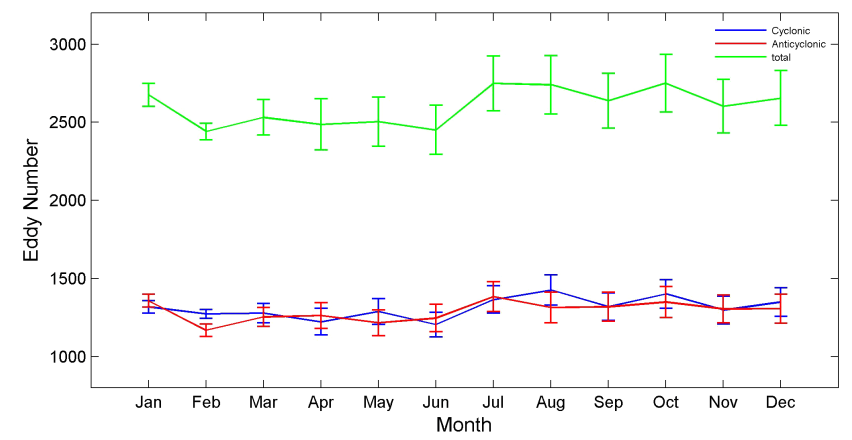

Figure 12. The number of mesoscale eddies generated in the SIO (1995-2012) as a function of the calendar months for cyclonic (blue), anticyclonic (red), and both types of eddies (green). The bars indicate the standard error of number of eddies. Mesoscale eddy data come from Chelton et al. (2011) based on altimetry observations of SSH. Chelton and Schlax have updated and extended the eddy data set to April 2012 in the new third version (http://cioss.coas.oregonstate.edu/eddies/).

The vertical velocity shear associated with the SICC and SEC system intensifies due to enhanced heat flux forcing of combined meridional Ekman and geostrophic convergence in austral spring (Jia et al., 2011). The seasonal change of baroclinic instability and EKE variations, induced by modulation of vertical velocity shear in the southeast Indian Ocean, favor the generation of eddies. In addition, other nonlocal processes including the Leeuwin Current (Feng et al., 2007; Rennie et al., 2007) and Agulhas Current systems (Backeberg et al., 2008; Beal et al., 2011) may also modulate the activity of mesoscale eddies. The mechanism of temporal variations of eddies needs further study.

\section{Discussion and conclusions}

The dynamics of submesoscale eddies are distinct from the traditional mesoscale quasi-geostrophic theory (Thomas et al., 2008), and in situ submesoscale observations are still relatively scarce. From model studies in the Southern California Bight, most eddies are in geostrophic balance, but some submesoscale eddies are ageostrophic with a finite value of the local Rossby number (Dong et al., 2012). The spatial distributions of submesoscale eddies are different from those of large eddies and may be controlled by ageostrophic balance, including pressure gradient, Coriolis acceleration and nonlinear effect. The submesoscale eddies are densely distributed over the entire SIO, with many submesoscale anticyclonic eddies in the subtropical basin in the central SIO (Fig. 9d), possibly attributable to submesoscale coherent vortices (SCVs). The SCVs have scales not exceeding the first baroclinic radius of deformation and are usually anticyclonic (Thompson and Young, 1989). McWilliams (1985) proposed the mechanism of anticyclonic SCVs, produced by geostrophic adjustment when a volume of water with weak stratification created by diapycnal mixing is injected into a more stratified fluid. This mechanism has been demonstrated in laboratory models (e.g., Hedstrom and Armi, 1988). Nencioli et al. (2013) estimated in situ submesoscale horizontal eddy diffusivity across an ocean front in the western Gulf of Lion in the Mediterranean Sea, which may extend our understanding about submesoscale process with more in situ observations in the future.

Eddy characteristics in the SIO were investigated on the basis of in situ satellite-tracked drifter data from 1979 to 2013. In total 19252 eddies were detected. Among them 7657 (11 595) are cyclonic (anticyclonic) eddies. For the submesoscale eddies, the ratio of cyclonic eddies (3183) to anticyclonic eddies (7182) is 1 to 2 . Large eddies $(r \geq 100 \mathrm{~km})$ populate the Leeuwin Current, a band along $25^{\circ} \mathrm{S}$, Mozambique Channel, and Agulhas Current. The spatial distribution of large eddies corresponds to the large EKE region (Figs. 9a, 10). In the Mozambique Channel, the shape of large eddies is restrained by coastline in the northeastsouthwest direction. The number of mesoscale eddies shows significant seasonal variations, consistent with eddies in the SIO detected from altimetry observations.

Acknowledgements. We thank Wei Zhuang for useful discussions and comments. The satellite-tracked drifter data were provided by the Drifter Data Assembly Center (DAC) at NOAA's Atlantic Oceanographic and Meteorological Labo- 
ratory (http://www.aoml.noaa.gov/envids/gld/index.php). The drifter-derived mean flow data were also provided by DAC (http://www.aoml.noaa.gov/phod/dac/dac_meanvel.php). The mesoscale eddies data detected by altimeter observation were obtained from mesoscale eddies in altimeter observation of SSH (http://cioss.coas.oregonstate.edu/eddies/). The SLA data were provided by AVISO (http://www.aviso.altimetry.fr/en/home.html). This work was supported by the Strategic Priority Research Program of the Chinese Academy of Sciences (XDA11010103), the Natural Science Foundation of China (41306018), the National Basic Research Program of China (2010CB950302, 2012CB955603), and the Knowledge Innovation Program of the Chinese Academy of Sciences (SQ201108).

Edited by: J. M. Huthnance

\section{References}

Abraham, E. R.: The generation of plankton patchiness by turbulent stirring, Nature, 391, 577-580, doi:10.1038/35361, 1998.

Abraham, E. R., Law, C. S., Boyd, P. W., Lavender, S. J., Maldonado, M. T., and Bowie, A. R.: Importance of stirring in the development of an iron-fertilized phytoplankton bloom, Nature, 407, 727-730, doi:10.1038/35037555, 2000.

Aristegui, J., Tett, P., HernandezGuerra, A., Basterretxea, G., Montero, M. F., Wild, K., Sangra, P., HernandezLeon, S., Canton, M., GarciaBraun, J. A., Pacheco, M., and Barton, E. D.: The influence of island-generated eddies on chlorophyll distribution: A study of mesoscale variation around Gran Canaria, DeepSea Res. Pt. I, 44, 71-96, doi:10.1016/S0967-0637(96)00093-3, 1997.

Backeberg, B. C., Johonnessen, J. A., Bertino, L., and Reason, C. J.: The greater Agulhas Current system: An integrated study of its mesoscale variability, Journal of Operational Oceanography, 1, 29-44, 2008.

Beal, L. M., de Ruijter, W. P. M., Biastoch, A., Zahn, R., and SCOR/WCRP/IAPSO Working Group 136: On the role of the Agulhas system in ocean circulation and climate, Nature, 472, 429-436, doi:10.1038/Nature09983, 2011.

Berti, S., Dos Santos, F. A., Lacorata, G., and Vulpiani, A.: Lagrangian Drifter Dispersion in the Southwestern Atlantic Ocean, J. Phys. Oceanogr., 41, 1659-1672, doi:10.1175/2011jpo4541.1, 2011.

Chaigneau, A. and Pizarro, O.: Eddy characteristics in the eastern South Pacific, J. Geophys. Res.-Oceans, 110, C06005, doi:10.1029/2004jc002815, 2005.

Chelton, D. B., DeSzoeke, R. A., Schlax, M. G., El Naggar, K., and Siwertz, N.: Geographical variability of the first baroclinic Rossby radius of deformation, J. Phys. Oceanogr., 28, 433460, doi:10.1175/1520-0485(1998)028<0433:Gvotfb>2.0.Co;2, 1998.

Chelton, D. B., Schlax, M. G., and Samelson, R. M.: Global observations of nonlinear mesoscale eddies, Prog. Oceanogr., 91, 167-216, doi:10.1016/j.pocean.2011.01.002, 2011.

Crawford, W. R., Brickley, P. J., Peterson, T. D., and Thomas, A. C.: Impact of Haida Eddies on chlorophyll distribution in the Eastern Gulf of Alaska, Deep-Sea Res. Pt. II, 52, 975-989, doi:10.1016/j.dsr2.2005.02.011, 2005.
Cresswell, G. R.: The Leeuwin Current - observations and recent models, Journal of the Royal Society of Western Australia, 74, 1-14, 1991.

Cresswell, G. R. and Golding, T. J.: Observations of a south-flowing current in the southeastern Indian Ocean, Deep-Sea Res. Pt. I, 27A, 449-466, 1980.

de Ruijter, W. P. M., Ridderinkhof, H., Lutjeharms, J. R. E., Schouten, M. W., and Veth, C.: Observations of the flow in the Mozambique Channel, Geophys. Res. Lett., 29, 1502, doi:10.1029/2001g1013714, 2002.

de Ruijter, W. P. M., van Aken, H. M., Beier, E. J., Lutjeharms, J. R. E., Matano, R. P., and Schouten, M. W.: Eddies and dipoles around South Madagascar: formation, pathways and large-scale impact, Deep-Sea Res. Pt. I, 51, 383-400, doi:10.1016/j.dsr.2003.10.011, 2004.

Deverdiere, A. C.: Lagrangian Eddy Statistics from Surface Drifters in the Eastern North-Atlantic, J. Mar. Res., 41, 375-398, 1983.

Dong, C., McWilliams, J. C., Liu, Y., and Chen, D.: Global heat and salt transports by eddy movement, Nature Communications, 5, 1-6, doi:10.1038/ncomms4294, 2014.

Donners, J. and Drijfhout, S. S.: The Lagrangian view of South Atlantic Interocean exchange in a global ocean model compared with inverse model results, J. Phys. Oceanogr., 34, 1019-1035, doi:10.1175/1520-0485(2004)034<1019:Tlvosa>2.0.Co;2, 2004.

Dong, C., Lin, X., Liu, Y., Nencioli, F., Chao, Y., Guan, Y., Chen, D., Dickey, T., and McWilliams, J. C.: Three-dimensional oceanic eddy analysis in the Southern California Bight from a numerical product, J. Geophys. Res.-Oceans, 117, C00H14, 2012.

Dong, C. M., Liu, Y., Lumpkin, R., Lankhorst, M., Chen, D., McWilliams, J. C., and Guan, Y. P.: A Scheme to Identify Loops from Trajectories of Oceanic Surface Drifters: An Application in the Kuroshio Extension Region, J. Atmos. Ocean. Tech., 28, 1167-1176, doi:10.1175/Jtech-D-10-05028.1, 2011.

Falkowski, P. G., Ziemann, D., Kolber, Z., and Bienfang, P. K.: Role of Eddy Pumping in Enhancing Primary Production in the Ocean, Nature, 352, 55-58, doi:10.1038/352055a0, 1991.

Feng, M., Wijffels, S., Godfrey, J. S., and Meyers, G.: Do eddies play a role in the momentum balance of the Leeuwin Current? J. Phys. Oceanogr., 35, 964-975, 2005.

Feng, M., Majewski, L. J., Fandry, C. B., and Waite, A. M.: Characteristics of two counter-rotating eddies in the Leeuwin Current system off the Western Australian coast, Deep-Sea Res. Pt. I, 54, 961-980, doi:10.1016/j.dsr2.2006.11.022, 2007.

Fieux, M., Molcard, R., and Morrow, R.: Water properties and transport of the Leeuwin Current and eddies off Western Australia, Deep-Sea Res. Pt. I, 52, 1617-1635, 2005.

Godfrey, J. S. and Ridgway, K. R.: The large-scale environment of the poleward-flowing Leeuwin Current, Western Australia: longshore steric height gradients, wind stresses, and geostrophic flow. J. Phys. Oceanogr. 15, 481-495, 1985.

Gordon, A. L., Weiss, R. F., Smethie, W. M., and Warner, M. J.: Thermocline and Intermediate Water Communication between the South-Atlantic and Indian Oceans, J. Geophys. Res.-Oceans, 97, 7223-7240, doi:10.1029/92jc00485, 1992.

Hamilton, P.: Eddy statistics from Lagrangian drifters and hydrography for the northern Gulf of Mexico slope, J. Geophys. Res.Oceans, 112, C09002, doi:10.1029/2006jc003988, 2007. 
Hansen, D. and Herman A.: Temporal sampling requirements for surface drifting buoys in the tropical Pacific. J. Atmos. Ocean. Tech., 6, 599-607, 1989.

Hansen, D. V. and Poulain, P. M.: Quality control and interpolations of WOCE-TOGA drifter data, J. Atmos. Ocean. Tech., 13, 900909, doi:10.1175/1520-0426(1996)013<0900:qcaiow>2.0.co;2, 1996.

Hedstrom, K. and Armi, L. An experimental study of homogeneous lenses in a stratified rotating fluid, Journal of Fluid Dynamics 191, 535-556, 1988.

Jia, F., Wu, L., and Qiu, B.: Seasonal Modulation off Eddy Kinetic Energy and Its Formation Mechanism in the Southeast Indian Ocean, J. Phys. Oceanogr., 41, 657-665, doi:10.1175/2010jpo4436.1, 2011.

Lankhorst, M.: A self-contained identification scheme for eddies in drifter and float trajectories, J. Atmos. Ocean. Tech., 23, 15831592, doi:10.1175/Jtech1931.1, 2006.

Lankhorst, M. and Zenk, W.: Lagrangian observations of the middepth and deep velocity fields of the northeastern Atlantic Ocean, J. Phys. Oceanogr., 36, 43-63, doi:10.1175/jpo2869.1, 2006.

Ledwell, J. R., Watson, A. J., and Law, C. S.: Evidence for Slow Mixing across the Pycnocline from an OpenOcean Tracer-Release Experiment, Nature, 364, 701-703, doi:10.1038/364701a0, 1993.

Lévy, M. and Klein, P.: Does the low frequency variability of mesoscale dynamics explain a part of the phytoplankton and zooplankton spectral variability?, P. R. Soc. London, 460, 16731683, 2004.

Lévy, M., Klein, P., and Tréguier, A. M.: Impacts of submesoscale physics on phytoplankton production and subduction, J. Mar. Res., 59, 535-565, 2001.

Li, J., Zhang, R., and Jin, B.: Eddy characteristics in the northern South China Sea as inferred from Lagrangian drifter data, Ocean Sci., 7, 661-669, doi:10.5194/os-7-661-2011, 2011.

Lumpkin, R. and Johnson, G. C.: Global ocean surface velocities from drifters: Mean, variance, El Niño-Southern Oscillation response, and seasonal cycle, J. Geophys. Res.-Oceans, 118, 29923006, doi:10.1002/Jgrc.20210, 2013.

Lumpkin, R. and Pazos, M.: Measuring surface currents with Surface Velocity Program drifters: the instrument, its data, and some recent results, Lagrangian analysis and prediction of coastal and ocean dynamics, 39-67, 2007.

Maximenko, N., Hafner, J., and Niiler, P.: Pathways of marine debris derived from trajectories of Lagrangian drifters, Mar. Pollut. Bull., 65, 51-62, doi:10.1016/j.marpolbul.2011.04.016, 2012.

McWilliams, J. C.: Submesoscale, coherent vortices in the ocean, Rev. Geophys., 23, 165-182, 1985.

McWilliams, J. C.: The Nature and Consequences of Oceanic Eddies, in: Ocean Modeling in an Eddying Regime, edited by: Hecht, M. W. and Hasumi, H., American Geophysical Union, Washington, D. C., USA, 5-15, doi:10.1029/177GM03, 2013.

Morrow, R., Birol, F., Griffin, D., and Sudre, J.: Divergent pathways of cyclonic and anti-cyclonic ocean eddies, Geophys. Res. Lett., 31, L24311, doi:10.1029/2004g1020974, 2004.

Nencioli, F., d'Ovidio, F., Doglioli, A. M., and Petrenko, A. A.: In situ estimates of submesoscale horizontal eddy diffusivity across an ocean front, J. Geophys. Res.-Oceans, 118, 7066-7080, doi:10.1002/2013jc009252, 2013.
Nakamura, T., Matthews, J. P., Awaji, T., and Mitsudera, H.: Submesoscale eddies near the Kuril Straits: Asymmetric generation of clockwise and counterclockwise eddies by barotropic tidal flow, J. Geophys. Res.-Oceans, 117, C12014, 2012.

Palastanga, V., van Leeuwen, P. J., and de Ruijter, W. P. M.: A link between low-frequency mesoscale eddy variability around Madagascar and the large-scale Indian Ocean variability, J. Geophys. Res.-Oceans, 111, C09029, doi:10.1029/2005jc003081, 2006.

Pearce, A. F.: Eastern boundary currents of the Southern Hemisphere. Proceedings of the Royal Society of Western Australia, 74, 35-46, 1991.

Potemra, J. T.: Contribution of equatorial Pacific winds to southern tropical Indian Ocean Rossby waves, J. Geophys. Res., 106, 2407-2422, 2001.

Pujol, M. I. and Larnicol, G.: Mediterranean sea eddy kinetic energy variability from 11 years of altimetric data, J. Marine Syst., 58, 121-142, doi:10.1016/j.jmarsys.2005.07.005, 2005.

Qiu, B. and Chen, S. M.: Eddy-induced heat transport in the subtropical North Pacific from Argo, TMI, and altimetry measurements, J. Phys. Oceanogr., 35, 458-473, doi:10.1175/jpo2696.1, 2005.

Quartly, G. D. and Srokosz, M. A.: Eddies in the southern Mozambique Channel, Deep-Sea Res. Pt. I, 51, 69-83, doi:10.1016/j.dsr2.2003.03.001, 2004.

Quartly, G. D., Buck, J. J. H., Srokosz, M. A., and Coward, A. C.: Eddies around Madagascar - The retroflection re-considered, J. Marine Syst., 63, 115-129, doi:10.1016/j.jmarsys.2006.06.001, 2006.

Rennie, S. J., Pattiaratchi, C. P., and McCauley, R. D.: Eddy formation through the interaction between the Leeuwin Current, Leeuwin Undercurrent and topography, Deep-Sea Res. Pt. I, 54, 818-836, doi:10.1016/j.dsr2.2007.02.005, 2007.

Ridderinkhof, H., van der Werf, P. M., Ullgren, J. E., van Aken, H. M., van Leeuwen, P. J., and de Ruijter, W. P. M.: Seasonal and interannual variability in the Mozambique Channel from moored current observations, J. Geophys. Res.-Oceans, 115, C06010, doi:10.1029/2009jc005619, 2010.

Schott, F. A. and McCreary, J. P.: The monsoon circulation of the Indian Ocean, Prog. Oceanogr., 51, 1-123, doi:10.1016/S00796611(01)00083-0, 2001.

Schott, F. A., Xie, S. P., and McCreary, J. P.: Indian Ocean Circulation and Climate Variability, Rev Geophys, 47, Rg1002, doi:10.1029/2007rg000245, 2009.

Schouten, M. W., de Ruijter, W. P. M., van Leeuwen, P. J., and Ridderinkhof, H.: Eddies and variability in the Mozambique Channel, Deep-Sea Res. Pt. II, 50, 1987-2003, 10.1016/s09670645(03)00042-0, 2003.

Schroeder, K., Chiggiato, J., Haza, A. C., Griffa, A., Ozgokmen, T. M., Zanasca, P., Molcard, A., Borghini, M., Poulain, P. M., Gerin, R., Zambianchi, E., Falco, P., and Trees, C.: Targeted Lagrangian sampling of submesoscale dispersion at a coastal frontal zone, Geophys. Res. Lett., 39, L11608, doi:10.1029/2012g1051879, 2012.

Swart, N. C., Lutjeharms, J. R. E., Ridderinkhof, H., and de Ruijter, W. P. M.: Observed characteristics of Mozambique Channel eddies, J. Geophys. Res.-Oceans, 115, C09006, 2010.

Thomas, L. N., Tandon, A., and Mahadevan, A.: Submesoscale processes and dynamics, Eddy Resolving Ocean Modeling, edited 
by: Hecht, M. W. and Hasumi, H., Amer. Geophys. Union, 1738, 2008.

Thompson, L. and Young, W. R.: An Upper Bound on the Size of Sub-mesoscale Coherent Vortices, J. Phys. Oceanogr., 19, 233-237, doi:10.1175/15200485(1989)019<0233:AUBOTS>2.0.CO;2, 1989.

Van Sebille, E., England, M. H., and Froyland, G.: Origin, dynamics and evolution of ocean garbage patches from observed surface drifters, Environ. Res. Lett., 7, 044040, doi:10.1088/17489326/7/4/044040, 2012.
Volkov, D. L., Lee, T., and Fu, L.-L.: Eddy-induced meridional heat transport in the ocean, Geophys. Res. Lett., 35, L20601, doi:10.1029/2008g1035490, 2008.

Zhang Z. G., Wang W., and Qiu B.: Oceanic mass transport by mesoscale eddies, Science, 345, 322-324, doi:10.1126/science.1252418, 2014.

$\mathrm{Zu}, \mathrm{T}$. T., Chen, J., and Wang, D. X.: Detection of the Cyclonic Eddy in the Southwest of the South China Sea: From Remote Sensing Data and Drifter Buoys, Adv. Intel. Soft. Compu., 142, 153-159, 2012. 